characterization of antisera that immunoprecipitate this factor will allow us now to examine the interaction of CREB with other proteins that are necessary to form a cAMP-responsive transcription complex. The presence of two domains - the phosphorylation and dimerization domains - in the CREB molecule offers two different, though not mutually exclusive, modes of regulation. In vitro mutagenesis of the cloned CREB cDNA will reveal the relative importance of protein-protein interactions and phosphorylation in transcriptional regulation by cAMP.

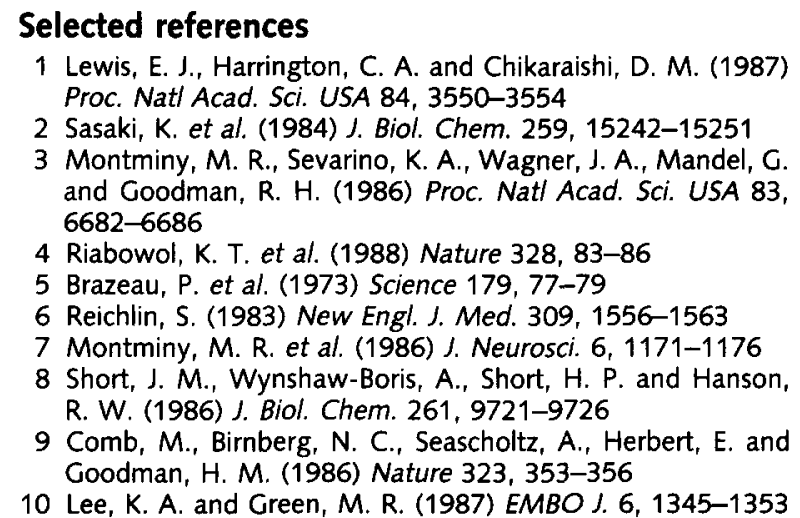

11 Montminy, M. R. and Bilezikjian, L. M. (1987) Nature 328 175-178

12 Yamamoto, K. K., Gonzalez, G. A., Biggs, W. H., III and Montminy, M. R. (1988) Nature 334, 494-498

13 Hardy, S. and Shenk, T. (1988) Proc. Nat/ Acad. Sci. USA 85 , $4171-4175$

14 Imagawa, M., Chiu, R. and Karin, M. (1987) Cell 51, 251-260

15 Williams, T., Admon, A., Luscher, B. and Tjoan, R. (1988) Genes Dev. 2, 1557-1569

16 Chiu, R., Imagawa, M., Imbra, R. J., Buckoven, J. R. and Karin, M. (1987) Nature 329, 648-651

17 Comb, M. et al. (1988) EMBO J. 7, 3793-3805

18 Comb, M., Birnberg, N. C., Seasholtz, A., Herbert, E. and Goodman, H. M. (1986) Nature 323, 353-356

19 Delegeane, A. M., Ferland, L. H. and Mellon, P. L. (1987) Mol. Cell. Biol. 7, 3994-4002

20 Horikoshi, M., Hai, T., Lin, Y. S., Green, M. R. and Roeder, R. G. (1989) Cell 54, 1033-1042

21 Gonzalez, G. A. et al. (1989) Nature 337, 749-752

22 Hoeffler, J. P., Meyer, T. E., Yum, Y., Jameson, J. L. and Habener, J. F. (1988) Science 242, 1430-1432

23 Gonzalez, J. A. and Montminy, M. R. (1989) Cell 59 , 675-680

24 Ma, J. and Ptashne, M. (1987) Cell 51, 113-119

25 Yamamoto, K. K., Gonzalez, G. A., Menzel, P., Rivier, J. and Montminy, M. R. Cell (in press)

26 Dwarki, J. J., Montminy, M. R. and Verma, I. M. (1990) $E M B O$ J. 9, 225-232

27 Chiu, R. et al. (1988) Cell 54, 541-552

28 Landshultz, W. H., Johnson, P. F. and McKnight, S. L. (1988) Science 240, 1759-1765

\title{
Developmental neurobiology of salt taste sensation
}

\author{
David L. Hill and Charlotte M. Mistretta
}

David L. Hill is at the Department of Psychology,

University of Virginia Charlottesville,

VA 22903, USA and Charlotte M.

Mistretta is at the

Department of

Biologic and Material

Sciences, School of

Dentistry and Center

for Human Growth

and Development

University of

Michigan, Ann Arbor,

MI 48109, USA.
A principal process in the homeostatic control of sodium levels is salt intake, and the sense of taste has a primary role in regulating ingestion. Because ingestion of sodium chloride $(\mathrm{NaCl})$ is essential for life, the taste system for salt sensation might be expected to exhibit mature functional characteristics from very early development. However, major changes in gustatory nerve responses to $\mathrm{NaCl}$ take place during development. In sheep and rat, the peripheral nerve responses to $\mathrm{NaCl}$ are of low magnitude during early development. Progressively, the taste system acquires an increasing proportion of fibers that respond maximally to $\mathrm{NaCl}$. The sodium responsiveness emerges in the context of shifting peripheral innervation patterns and the apparent addition of functional receptor membrane channels sensitive to the sodium transport blocker, amiloride. These developmental processes can be altered by early manipulation of sodium in the diet.

Ingestion of salt is a crucial first step in the series of regulatory mechanisms that maintain appropriate extracellular concentrations of the electrolyte, sodium. The primary sensory system that operates in detection, recognition and ingestion of $\mathrm{NaCl}$ is taste. Because ingestion of sodium is essential for life, it might be assumed that receptor mechanisms for sodium taste develop and mature early, and remain resistant to environmental manipulation. On the contrary, the sodium taste system matures gradually during development and, at least in early stages, is susceptible to environmental alterations.

In this review, we describe systematic, profound changes that take place during mammalian develop- ment in the response to sodium as a taste stimulus. Our goal is to discuss the neural basis of these changes against a background of recent progress in understanding the molecular and cellular aspects of salt taste reception in the adult ${ }^{1-3}$. The discussion will not only describe emerging processes crucial in salt taste sensation, but also aspects of the developmental neurobiology of the peripheral taste system. The focus of this review is on the functional development of taste buds and afferent innervation, and therefore, we will not discuss a growing body of evidence that demonstrates alterations in the taste areas of the CNS during development ${ }^{4,5}$. However, these central changes obviously have an important role in the maturation of salt intake.

Taste buds are dependent on gustatory innervation for development, maintenance, and regeneration ${ }^{6,7}$. There is a constant turnover of taste receptor cells throughout life ${ }^{8}$, and therefore, synapses between taste cells and afferent nerve fibers are presumably continually remodeled. Since receptors and neural connections are in a state of constant change, the gustatory system exhibits a degree of complexity and prolonged plasticity not found in other parts of the PNS. Thus, the taste system provides unique opportunities to study a system that is continually changing, even after completion of initial developmental processes.

\section{Mechanisms of salt taste reception}

Beidler and co-workers demonstrated in the early 1950 s that the cation fulfilled the primary role in salt taste stimulation, and concluded that various cations 
stimulate different receptor sites in the taste cell membrane ${ }^{9}$. A variety of subsequent studies provided neurophysiological and behavioral evidence demonstrating that $\mathrm{NaCl}$ and lithium chloride $(\mathrm{LiCl})$ act similarly on the taste system and in a very different manner to potassium chloride $(\mathrm{KCl})$ and ammonium chloride $\left(\mathrm{NH}_{4} \mathrm{Cl}\right)^{10-12}$. Ideas about transduction mechanisms for the various salts have altered substantially from the initial studies, and in the past decade experiments with the sodium transport blocker, amiloride, have refined our understanding of sodium taste reception in particular. In humans, the perceived taste intensity of $\mathrm{NaCl}$ is reduced if amiloride is first applied to the tongue epithelium ${ }^{13}$. Neurophysiological responses to $\mathrm{NaCl}$ recorded from taste afferent nerve fibers in rodents are decreased in the presence of amiloride $^{14,15}$. Experiments with in vitro preparations of tongue epithelium indicate that the shortcircuit current of sodium across canine epithelium is reduced after the addition of amiloride to the tongue dorsum ${ }^{16}$. Generally, the effects of amiloride on salt taste reception are limited to sodium and lithium salts, with relatively minimal effects on the taste reception of other salts.

Thus, experiments with amiloride have supported earlier reports on the existence of a separate gustatory receptor system for sodium and lithium salts and have further suggested that sodium channels in taste cell membranes are involved in sodium reception. Recently, the existence of multiple ion channels in taste receptor cells, including an amiloride-sensitive channel in some species, has been demonstrated with patch-clamp techniques ${ }^{2,16}$.

\section{Salt receptor systems throughout development}

Just as knowledge about mechanisms of salt taste sensation has progressed through recent advances attributable to biophysical approaches, other important insights have derived from developmental studies. For example, we know that responses to various monochloride salts emerge at different times, that there are orderly developmental changes in the sensitivities of receptor cells for salts and the changes are different for different salts, and that peripheral nerve rearrangements take place in concert with changes in the taste buds.

Changes in the effectiveness of sodium during preand postnatal development in sheep. The sheep is an appropriate animal for studying the neurophysiological development of the gustatory system because the time course of taste bud development is similar to that in humans, and the fetus is amenable to experimental manipulation. Taste buds appear at about day 50 of gestation in sheep (full term is about 150 days) and at

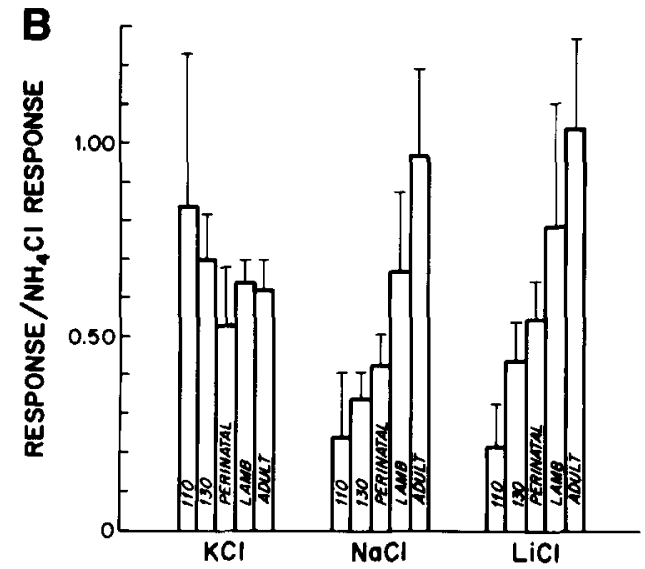

Fig. 1. Development of salt taste responses in sheep. (A) Responses from multifiber preparations of the chorda tympani nerve from a sheep fetus at day 114 of gestation (full term is about 150 days) provides a measure of the response magnitude Stimuli applied to the anterior tongue were $0.5 \mathrm{M}$ teady-state portion of the response was measured $20 \mathrm{~s}$ after stimulus onset. Responses to $\mathrm{NaCl}$

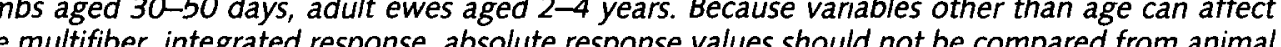
the multifiber, rather, a response ratio should be used. For a reference chemical 0.

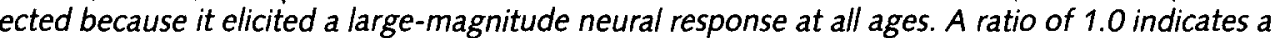

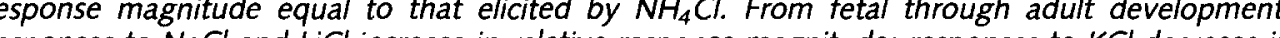
responses to $\mathrm{NaCl}$ and $\mathrm{LiCl}$ increase in relative response magnitude; responses to $\mathrm{KCl}$ decrease in relative magnitude during prenatal development, and then remain stable. (Taken, with permission

about week $7-8$ of gestation in humans (full term is about 280 days $)^{17}$. Thus, taste receptor cell structures form very early in mammals with lengthy gestations. Furthermore, neurophysiological recordings from the sheep chorda tympani nerve, which innervates taste buds in fungiform papillae on the anterior tongue, reveal that receptors respond to a variety of chemical stimuli for at least the last third of gestation $^{17,18}$.

Although taste receptors become functional early in prenatal life, the system does not respond in a mature manner from the outset ${ }^{18}$. Recordings from the chorda tympani nerve demonstrate that responses to $\mathrm{NaCl}$ and $\mathrm{LiCl}$ are of very small magnitude in the youngest fetuses compared with responses to $\mathrm{NH}_{4} \mathrm{Cl}$ and $\mathrm{KCl}$ (Fig. 1). In adult sheep, responses to $\mathrm{NaCl}$, $\mathrm{LiCl}$ and $\mathrm{NH}_{4} \mathrm{Cl}$ are all similar in response magnitude, and responses to $\mathrm{KCl}$ are small in comparison. Overall, results indicate that $\mathrm{NaCl}$ interacts with one array of receptor components, $\mathrm{KCl}$ with another, and $\mathrm{NH}_{4} \mathrm{Cl}$ with yet another. Most importantly for the present discussion, responses to $\mathrm{NaCl}$ increase during development compared with $\mathrm{NH}_{4} \mathrm{Cl}$. $\left(\mathrm{NH}_{4} \mathrm{Cl}\right.$ is appropriate as a standard, or reference, stimulus in multifiber recordings because it elicits a largemagnitude neural response at all ages.)

The developmentally related changes in salt sensitivities do not take place during a confined period of the sheep's life but progress over a prolonged portion of pre- and postnatal development (Fig. 1). Further work has extended these findings by showing that the proportion of single fibers maximally sensitive to $\mathrm{NaCl}$ increases during development compared with the proportion of fibers that are maximally sensitive to 

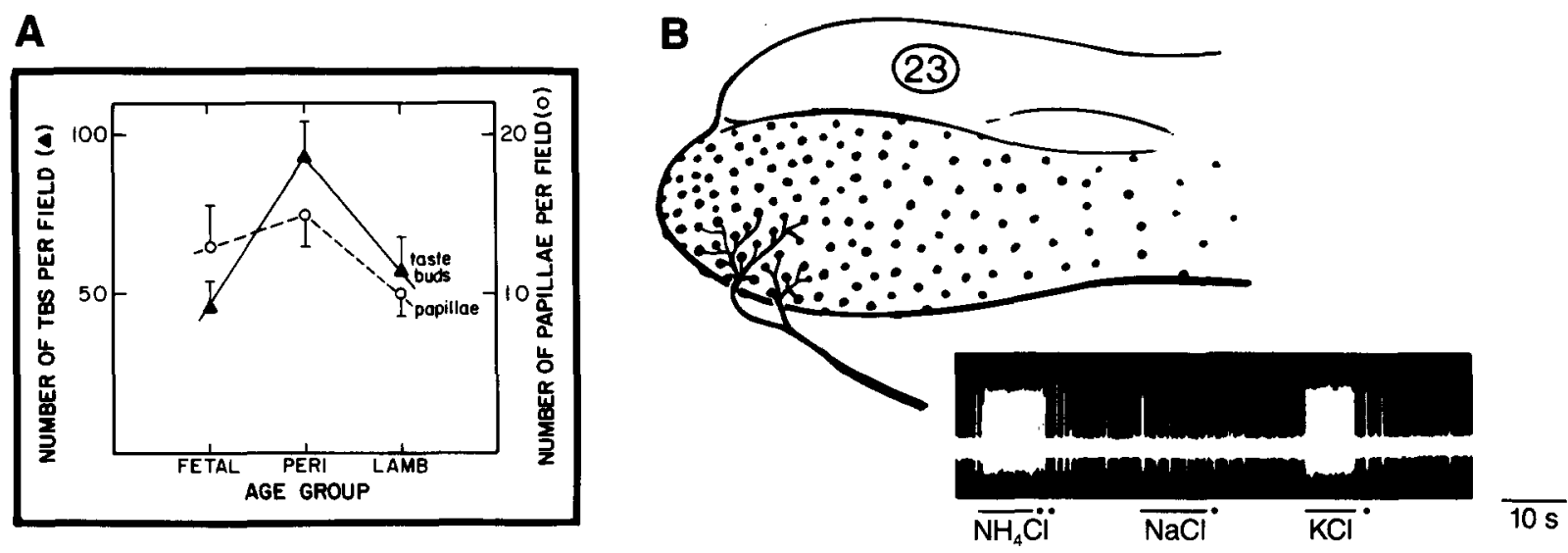

Fig. 2. Receptive field size and salt response characteristics from sheep. (A) Numbers of fungiform papillae and taste buds in 58 receptive fields. Means and standard errors are presented for three age groups: fetal, day 130 of gestation; perinatal, 7 days before or after birth; and lamb, 1-3 months after birth. The average number of papillae per receptive field is smaller in lambs than in younger age groups. The number of taste buds (TBs) per field is greater in perinatal animals than in fetuses or lambs. (Redrawn from Refs 19,22.) (B,C) Neurophysiological responses to stimulation of the tongue with $0.5 \mathrm{M} \mathrm{NH}_{4} \mathrm{Cl}, \mathrm{NaCl}$ and $\mathrm{KCl}$ are presented

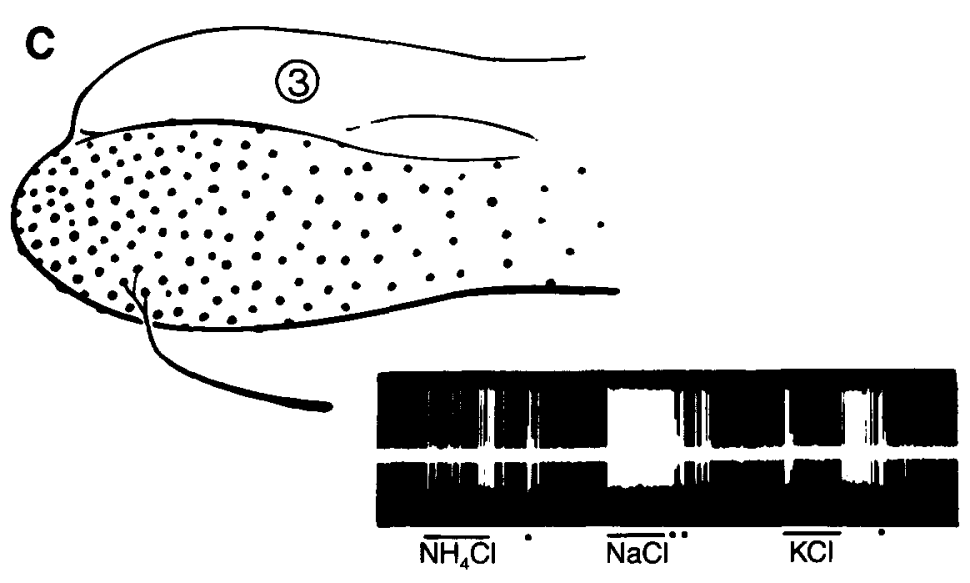
for two single chorda tympani nerve fibers, with schematics of receptive fields. Bars under neurophysiological records indicate the period of stimulus application, and dots denote water rinses. (B) Receptive field diagram and salt responses for a fiber from a perinatal animal. Based on responses to electrical stimulation of single papillae, the illustrated fiber innervated 23 fungiform papillae on the anterior tongue. Neurophysiological records demonstrate the very high response frequency to $\mathrm{NH}_{4} \mathrm{Cl}$ and low response frequency to $\mathrm{NaCl}$. (C) Receptive field diagram and salt responses for a single fiber from a postnatal lamb. The fiber innervated three fungiform papillae. Neural records indicate the very high frequency response to $\mathrm{NaCl}$. These two fibers illustrate the correlation between receptive field size and salt response; fibers maximally responsive to $\mathrm{NaCl}$ tend to have smaller receptive fields than those maximally responsive to $\mathrm{NH}_{4} \mathrm{Cl}$. Also, the fibers illustrate the developmental acquisition in lambs of a greater proportion of small, highly $\mathrm{NaCl}$-responsive receptive fields that complement existing, larger, more $\mathrm{NH}_{4} \mathrm{Cl}$-responsive fields.

$\mathrm{NH}_{4} \mathrm{Cl}^{19}$. Thus, the developmental increase in relative sensitivity to $\mathrm{NaCl}$ in the sheep chorda tympani relates to an acquisition of fibers that are maximally responsive to $\mathrm{NaCl}$.

Development of primary afferent receptive fields. As mentioned above, there is a constant turnover of taste receptor cells, yet they rely on gustatory nerves for their survival. As cells die and are replaced, there is ample opportunity for the addition of new receptor membrane in the taste bud as well as altered neural connections. Therefore, an important topic for study is whether the innervation patterns of taste buds alter in relation to changing response sensitivities.

By recording from single chorda tympani fibers and applying punctate electrical stimulation to single fungiform papillae, the number of papillae innervated by individual taste afferents can be determined in fetal, perinatal and postnatal sheep ${ }^{19}$. Once the size and location of the receptive field are mapped, salt response characteristics of the field can be assessed by chemical stimulation. Such experiments reveal that there is a significant difference in the average number of papillae innervated by one fiber across the age groups studied. Receptive field size in postnatal lambs is smaller than that in younger animals (Fig. 2A). Thus, the taste system is similar to other examples of developmental reorganization in the PNS that involve a progression from larger, diffuse innervation patterns to smaller one ${ }^{20,21}$. The decrease in field size of taste fibers is accompanied by an increase in the proportion of fibers that respond with the highest frequency to $\mathrm{NaCl}$, rather than to $\mathrm{NH}_{4} \mathrm{Cl}$ or $\mathrm{KCl}$. Furthermore, receptive field size is correlated with responses to salts. Across age groups, single fibers that are maximally responsive to $\mathrm{NaCl}$ have smaller receptive fields than those maximally responsive to $\mathrm{NH}_{4} \mathrm{Cl}$ (Fig. 2). These results demonstrate that there is a developmental acquisition of an increased proportion of small, highly NaCl-responsive receptive fields in the peripheral taste system, and that these fields complement existing, larger, more $\mathrm{NH}_{4} \mathrm{Cl}$-responsive fields. Thus, at least two salt subsystems exist, and they mature at different times.

Associated with the emergence of $\mathrm{NaCl}$-responsive receptive fields, there is an increase and subsequent decrease in numbers of taste buds per receptive field (Fig. 2A), in average numbers of taste buds in individual fungiform papillae, and in total numbers of 
chorda tympani nerve fibers ${ }^{22}$. An apparent process of taste bud division or fission takes place during the period when increased numbers of taste buds and nerve fibers are acquired. All of these factors indicate that a series of complex neural rearrangements underlies the development of salt taste receptive fields.

A working model of processes contributing to these rearrangements has been proposed, and it includes consideration of the contemporaneous acquisition of receptor membrane for $\mathrm{NaCl}$, excess production and subsequent loss of taste buds, and hyperinnervation and subsequent decrease in the distribution of afferent fibers to taste buds ${ }^{23}$. Within the model, $\mathrm{NaCl}$ responsive receptor membrane could be added under the influence of new innervation or could arise independently and then specify $\mathrm{NaCl}$ sensitivity in fibers. Alternatively, either innervating fibers could compete for receptor membrane within the target field, and the competition process could determine the fate and/or response properties of the fibers, or both fibers and membranes could acquire specific response characteristics independently and then 'match' during the innervation process. In any event, salt taste receptive fields are not static during development, but undergo substantial changes in receptor morphology, size, response characteristics and neural organization.

Neurophysiological taste responses in rat. Unlike sheep, the taste system in rat develops almost exclusively postnatally (Fig. 3A,B) ${ }^{24,25}$. Remarkably, however, the direction of changes in salt taste responses from the rat chorda tympani nerve parallels that in sheep. That is, the gustatory system in rat shows a progressive and prolonged increase in sodium responsiveness (Fig. $3 \mathrm{C})^{26-28}$ comparable to that illustrated for sheep in Fig. 1. Single fiber recordings from the rat chorda tympani demonstrate that the change in relative responses can be attributed to an increase in $\mathrm{NaCl}$ sensitivity ${ }^{29}$. Response frequencies of single fibers to $\mathrm{NaCl}$ increase twofold during development; whereas those to $\mathrm{NH}_{4} \mathrm{Cl}$ remain unchanged. Moreover, as found in sheep, the number of fibers maximally responsive to $\mathrm{NaCl}$ increases relative to the number of fibers maximally responsive to $\mathrm{NH}_{4} \mathrm{Cl}$ (Fig. 3C). Although these striking functional similarities exist between two species with widely different developmental histories, it is important to note that this pattern is not observed in all mammals $(\text { see Box } 1)^{30}$.

The sodium transport blocker, amiloride, has been used to probe factors that account for the developmental increase in taste receptor responses to $\mathrm{NaCl}^{31}$. As briefly discussed, amiloride has provided evidence for a rather specific sodium transport pathway that is involved in sodium transduction in adults. By applying amiloride to the tongues of rats at different ages, it is apparent that the developmental increase in chorda tympani nerve responses to $\mathrm{NaCl}$ occurs concomitantly with an increase in sensitivity to amiloride. In rats aged 12-13 days, which have a small neural response to $\mathrm{NaCl}$, amiloride is ineffective in suppressing responses to $\mathrm{NaCl}$. In older rats, amiloride blocks the response to $\mathrm{NaCl}$ to an extent that equals the increase in sodium sensitivity. That is, amiloride reduces the $\mathrm{NaCl}$ response to a constant magnitude - the magnitude corresponding to that observed in early postnatal rats. These results and
Box 1. Salt taste development in hamster

The hamster provides an excellent animal model for examining normal environmental constraints and pressures on the developing salt taste system. Unlike the rat and sheep, which inhabit mesophytic environments, the hamster must cope with pressures related to a dry, xerophytic environment. Therefore, the rat and sheep use different adaptation mechanisms to regulate sodium, than does the hamster. Since rat and sheep ordinarily have abundant amounts of water available, sodium is conserved in order to maintain proper fluid volume. Sodium is also regulated closely in the hamster, but the cation is usually excreted instead of conserved in order to cope with the lack of fluid in the environment. Thus, rat and sheep inherently prefer sodium solutions, whereas the hamster avoids sodium solutions of any concentration ${ }^{50-52}$. Furthermore, rat and sheep increase sodium intake in response to acute sodium depletion, whereas the hamster does not ${ }^{51,53}$. As one might expect, the taste responses of peripheral nerves are very different in hamster than in rat and sheep (see figure). Responses of the chorda tympani nerve to $\mathrm{NaCl}$ in early postnatal hamsters are extremely large in relation to other stimuli and are blocked by amiloride ${ }^{30}$. The effectiveness of $\mathrm{NaCl}$ as a taste stimulus decreases during development compared with that of $\mathrm{NH}_{4} \mathrm{Cl}$. Thus, the developmental patterns for the hamster are opposite in direction to those in the rat and sheep.

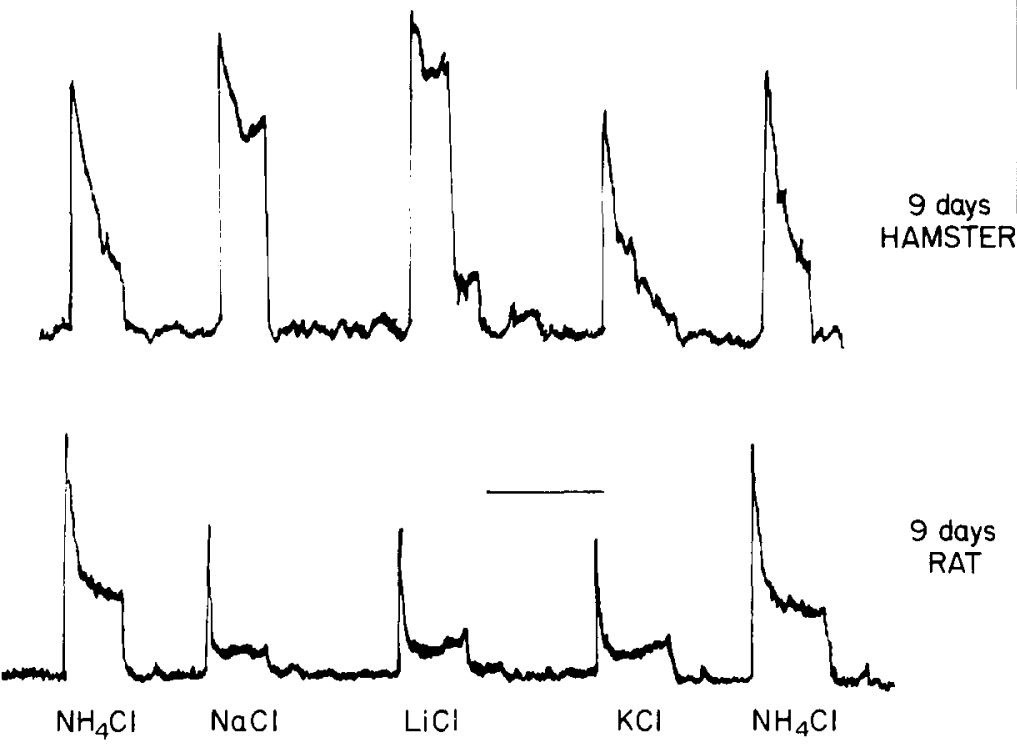

Integrated responses from the chorda tympani nerve to $0.1 \mathrm{M} \mathrm{NH}_{4} \mathrm{Cl}, \mathrm{NaCl}$, $\mathrm{LiCl}$ and $\mathrm{KCl}$ in a 9-day-old-hamster and a 9-day-old rat. Responses in hamster to $\mathrm{NaCl}$ and $\mathrm{LiCl}$, relative to the $\mathrm{NH}_{4} \mathrm{Cl}$ response, are much larger than those in rats. Scale bar is 40 s. (Taken, with permission, from Ref. 30.)

others ${ }^{32}$ indicate that the small response to $\mathrm{NaCl}$ in early postnatal rats might be mediated by a response to the halogen anion component of the salt. During subsequent development, receptor membrane channels that are blocked by amiloride are apparently added to the receptor, and it is these new channels that respond to the sodium cation.

\section{Early dietary sodium restriction and \\ alterations in sodium taste responses}

Research on other sensory systems has shown that the development of normal neurophysiological, anatomical and behavioral characteristics depends on specific features of early sensory stimulation ${ }^{33,34}$. For instance, either restricted or enhanced stimulation during development can modify sensory function, and the most dramatic effects occur when altered stimulation is instituted during the period of maximal functional change.

From our knowledge of the normal development of 
taste function, restricted or enhanced exposure to $\mathrm{NaCl}$ during early development should have profound influences on the developing gustatory system. Indeed, dramatic alterations in normal behavioral and functional taste responses are apparent when dietary exposure to $\mathrm{NaCl}$ is altered in rodents ${ }^{35,36}$. In rats exposed to low $\mathrm{NaCl}(0.03 \% \mathrm{NaCl})$ via maternal dietary restriction from embryonic day 3 to at least postnatal day 28 , chorda tympani nerve responses to sodium salts are lower compared with those of rats
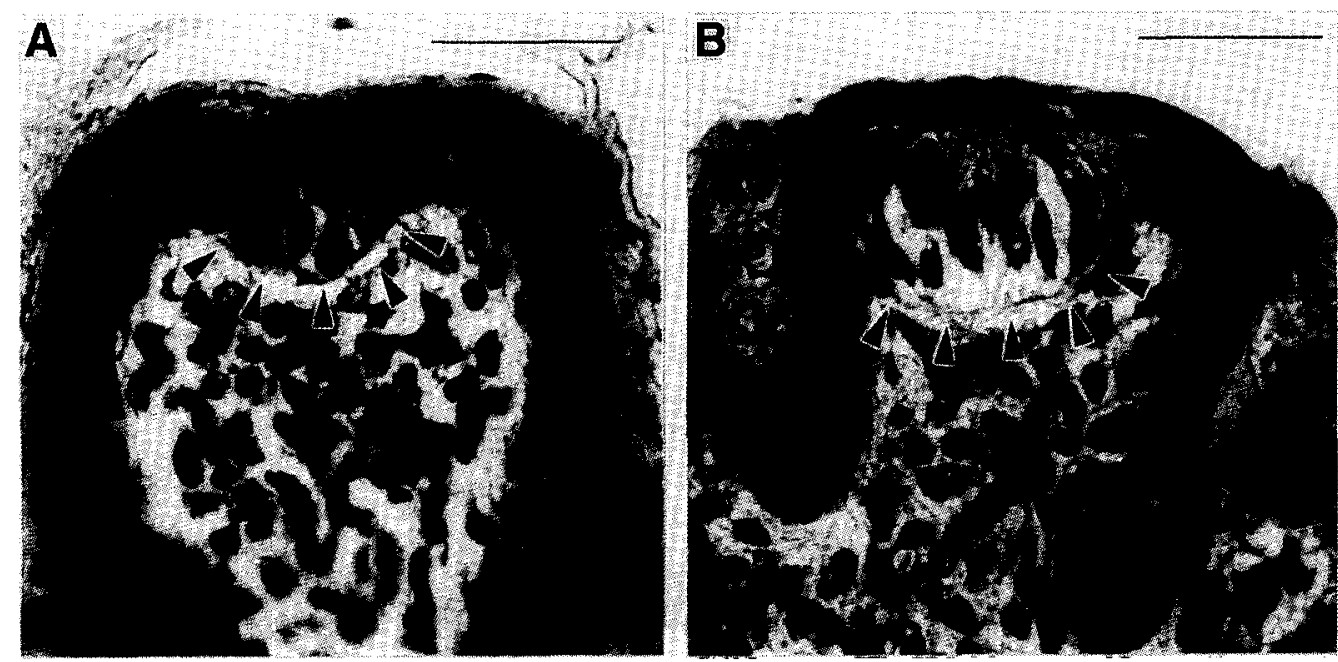

C
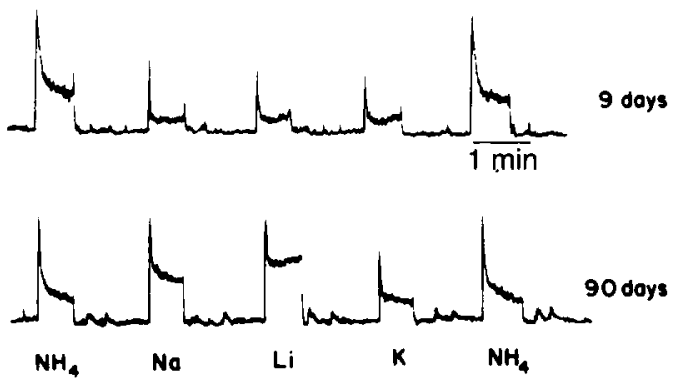

Fig. 3. $(\mathrm{A}, \mathrm{B})$ Photomicrographs of rat taste bud and fungiform papilla; hematoxylin and eosin stain. (A) Postnatal day 1. Lingual taste buds begin to form on the day before birth, and by postnatal day $1,75 \%$ of taste buds have this appearance. At this stage, the taste bud is a collection of cells without a distinct arrangement and cells have no direct connection with the oral cavity. (B) Postnatal day 20. About three weeks after birth, virtually all taste buds appear to be morphologically mature, as shown. The taste bud is ovoid in shape with oriented cells that have direct access to the oral cavity through the apical taste pore. Scale bars are $50 \mu \mathrm{m}$. Arrowheads point to the basement membrane of the taste bud, in the apex of the papilla. (C) Development of salt taste responses in rat. Left: responses from multifiber preparations of the chorda tympani nerve from a postnatal rat 9 days after birth, and a 90-day-old adult. Measures of the adapted response demonstrate an increase in response magnitude to $\mathrm{NaCl}$ and $\mathrm{LiCl}$, relative to $\mathrm{NH}_{4} \mathrm{Cl}$. (Taken, with permission, from Ref. 28.) These data can be compared with those in Fig. 1 to illustrate the similar developmental increases in $\mathrm{NaCl}$ taste responses in sheep and rat. Right: examples of single chorda tympani nerve fiber responses to $\mathrm{NH}_{4} \mathrm{Cl}, \mathrm{NaCl}, \mathrm{LiCl}$ and $\mathrm{KCl}$ in a young postnatal rat (top) and an adult (bottom). For each set of responses, the dots denote application of the stimulus and distilled water rinses. Not only do average response frequencies to $\mathrm{NaCl}$ and $\mathrm{LiCl}$ increase during development, but also the proportion of fibers that respond with very high frequency to $\mathrm{NaCl}$ increases significantly. fed a sodium-replete diet (Fig. 4A). Responses to non-sodium salts and non-salt stimuli are unaffected. The effects are reversible: chorda tympani responses salts increase to control levels after deprived rats are fed the replete diet for at least 15 ays ${ }^{35}$ peripheral gustatory system presumably relates to the formation of functional channels that are sensitive to amiloride ${ }^{35}$. For example, the reduced neural responses to $\mathrm{NaCl}$ that are observed in rats exposed to low $\mathrm{NaCl}$ diets are not further reduced during exposure of the tongue to amiloride. However, when deprived rats are fed the $\mathrm{NaCl}$ replete diet, an increase in amiloride sensitivity occurs in direct association with the increase in sensitivity to $\mathrm{NaCl}$. Therefore, the peripheral gustatory system in $\mathrm{NaCl}$-deprived rats might be functionally fixed in an immature state, comparable to that observed in early postnatal rats before functional amiloride-sensitive channels have been added to taste membranes. Addition of $\mathrm{NaCl}$ to the diet of deprived rats effects maturation of the $\mathrm{NaCl}$ receptor system.

It is important to note that if rats are initially fed the $\mathrm{NaCl}$-deficient diet as adults, there is no alteration in the integrated chorda tympani nerve response to $\mathrm{NaCl}$ expressed relative to the response to $\mathrm{NH}_{4} \mathrm{Cl}^{35}$. Therefore, $\mathrm{NaCl}$ deprivation during early development has dramatic and specific effects on peripheral taste responses. However, there is evidence that variations in the dietary sodium concentration may lead to different results. For example, rats fed a more concentrated diet of sodium $(0.08 \% \mathrm{NaCl})$ from conception to post-weaning ages apparently have normal chorda tympani responses ${ }^{37}$, and rats fed a sodium-free diet at adulthood reportedly have lowered neural responses to sodium ${ }^{38}$.

Prenatal and early postnatal events and the developmental fate of taste receptors. As described above, functional alterations in sodium sensitivity can be produced in rats if dietary sodium deprivation begins at day 3 of gestation but not when it begins in adulthood. Recently, however, the period of vulnerability, or sensitive period, has been shown to occur on or before day 8 of gestation ${ }^{39}$. When restriction of maternal dietary sodium is instituted on or before embryonic day 8 , taste responses 
to $\mathrm{NaCl}$ are reduced in the offspring. Instituting the low- $\mathrm{NaCl}$ diet at embryonic day 10 or later fails to produce alterations in sodium responses (Fig. 4B). Even if one assumes that there is a delay of a few days before fetuses 'experience' the effects of maternal deprivation, the end of the sensitive period in rats must still occur before the end of gestation, when taste buds normally form on the tongue ${ }^{24,25}$. Therefore, development of the initial membrane channels that apparently function in the eventual transduction of sodium taste information depends on very early, prenatal events and not on later, direct stimulation of taste receptors by sodium.

Other, indirect evidence for the absence of a direct stimulus-taste receptor interaction in forming functional amiloride-sensitive channels also derives from recovery of the lowered sodium response in deprived rats $^{40}$. We have observed recovery of chorda tympani taste responses to sodium even though deprived rats ingest $\mathrm{NaCl}$ during only one episode of drinking $30 \mathrm{ml}$ of isotonic saline. However, no recovery occurs if the natriuretic factor, furosemide, is injected immediately before and after ingestion of the single bout of saline. Thus, recovery is not dependent solely on direct receptor interactions with sodium but seems to be related to events subsequent to ingestion. The 'recovery' of sodium sensitivities may also involve hormonal or biochemical factors that are important in determining the fate of taste receptors during development, and the stimulation of taste receptors via $\mathrm{NaCl}$ in the blood ${ }^{41}$. In summary, the effect of early salt deprivation is profound at the receptor level; a sensitive period for determining the fate of receptor function occurs long before the emergence of the taste receptor and, therefore, does not parallel the system's period of maximal growth; finally, the effects of deprivation are completely reversible.

There is another apparent period of vulnerability slightly later in development, which is related to acquisition of taste buds after the loss of normal innervation ${ }^{42}$. Studies of taste buds in circumvallate papillae on the posterior rat tongue suggest that the lack of innervation during very early periods of initial taste bud formation has permanent effects on subsequent numbers of buds, even though the nerve is allowed to reinnervate gustatory tissue. If the glossopharyngeal nerve is surgically avulsed between postnatal days 0 and 10 , only about $50 \%$ of circumvallate taste buds form when the nerve reinnervates the posterior tongue. Once past the early formation of taste buds, such experimental manipulation has significantly less effect on regeneration.

Thus, there are at least two sensitive periods in the developing gustatory system: one apparently relates to modification of receptor membrane components and the other relates to the ability of an avulsed taste nerve to regenerate and form normal numbers of taste buds.

\section{Concluding remarks}

Figure 5 summarizes what is currently known about the development of sodium responsiveness in the peripheral gustatory system of mammals, based on studies of sheep and rat. The specific periods cannot necessarily be generalized to taste buds in all areas of the oropharynx or to all mammalian species.
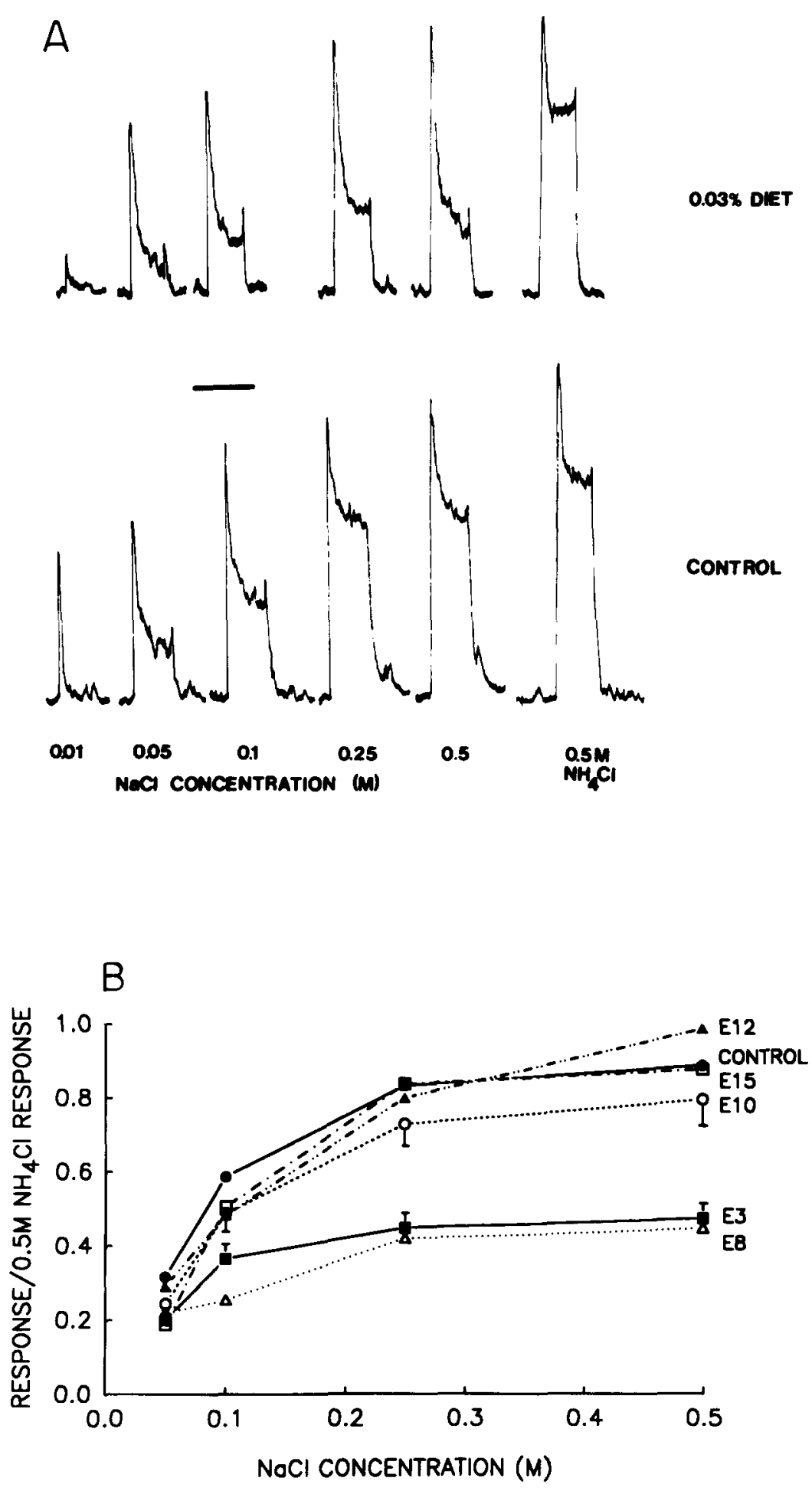

Fig. 4. (A) Neural responses from the chorda tympani nerve to a range of $\mathrm{NaCl}$ concentrations, and $0.5 \mathrm{M} \mathrm{NH} \mathrm{H}_{4} \mathrm{Cl}$, in a rat that experienced dietary sodium deprivation imposed at day 3 of gestation (top) and in a control animal fed an $\mathrm{NaCl}$-replete $\operatorname{diet}(1.0 \% \mathrm{NaCl}$ ) throughout development (bottom). All recordings were obtained when rats were 28-45 days old postnatally. To quantify data, the adapted, steady-state portion of the response was measured $20 \mathrm{~s}$ after stimulus onset. Responses to $\mathrm{NaCl}$, relative to the $\mathrm{NH}_{4} \mathrm{Cl}$ response, were lower in sodium-deprived rats than in controls. (Taken, with permission, from Ref. 34.) (B) Average ( \pm SEM) chorda tympani nerve responses to a range of $\mathrm{NaCl}$ concentrations in rats that experienced dietary sodium deprivation imposed at days 3, 8, 10,12 and 15 of gestation and in controls. Initiation of $\mathrm{NaCl}$ deprivation at days 3 and 8 of gestation decreased neural response magnitudes to $\mathrm{NaCl}$. Initiation of the dietary deprivation only two days later results in unaltered responses to $\mathrm{NaCl}$. (Taken, with permission, from Ref. 37. ) 


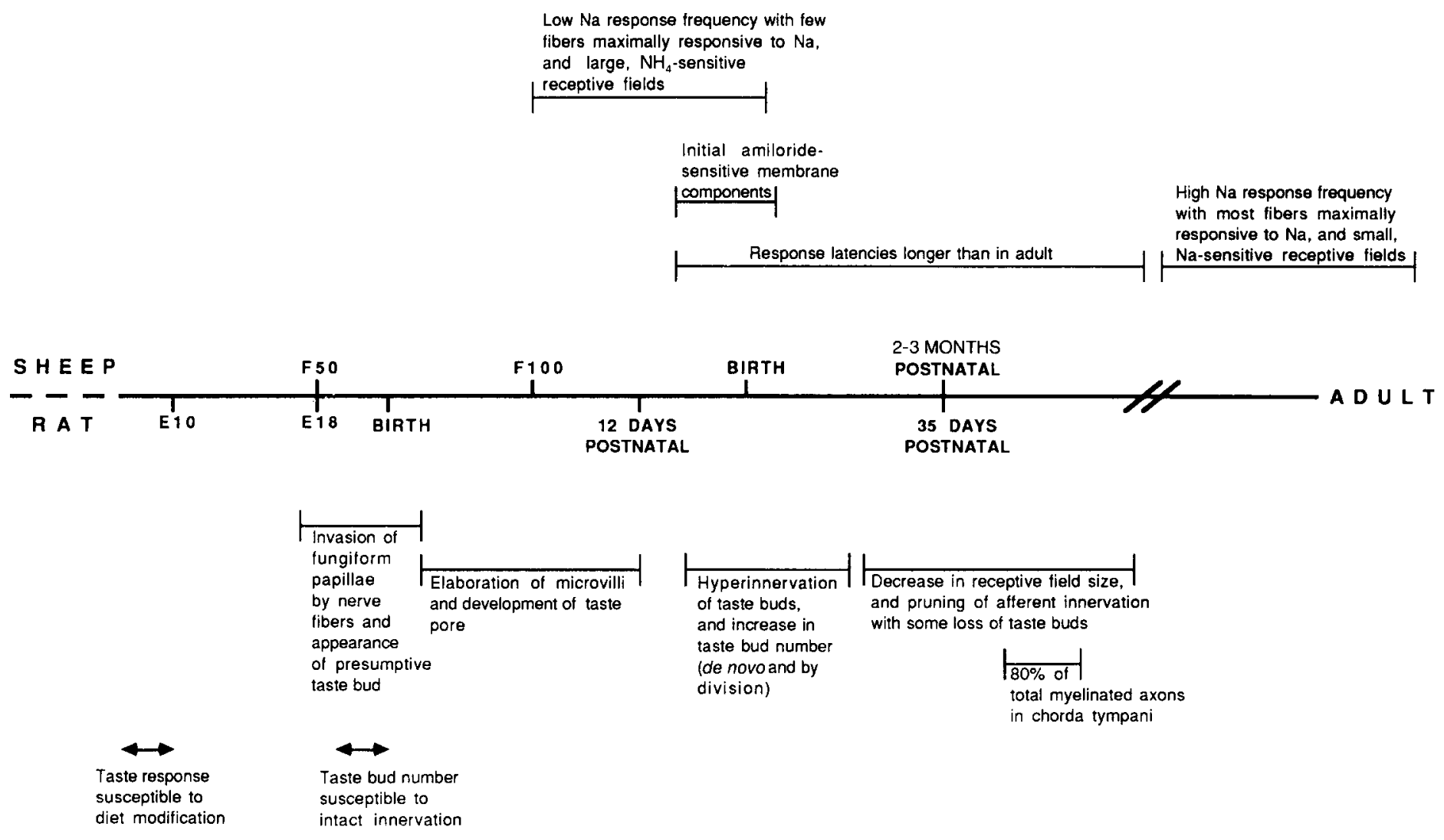

Fig. 5. Scheme of gustatory system development in sheep and rat. Ages for both species are matched approximately for neurophysiological events (denoted above the age line) and for anatomical events (denoted below the age line). Two 'sensitive periods' are identified in the lower portion of the figure, bracketed with arrowheads. The developmental periods for all events are estimates derived from literature cited in the text. (Format modeled on Ref. 54.)

During very early development, events occur that appear to determine the sodium sensitivity manifested by taste receptor cells later in development. This sensitive period represents a time of vulnerability when the developing gustatory system can be modified by environmental influences. Once past this period, effects due to the institution of environmental, dietary manipulations are highly attenuated or absent. There is also a later sensitive period of dependency on intact innervation for the acquisition of appropriate numbers of taste buds.

Even very early in normal taste bud development, receptor cells are capable of transducing taste information, and afferent fibers transmit this information to the brain. However, from the onset of function through a significant developmental period, the taste system has a low sensitivity to sodium (or perhaps no sensitivity) as reflected by a low response frequency to $\mathrm{NaCl}$, lack of amiloride sensitivity, few primary afferent fibers maximally sensitive to $\mathrm{NaCl}$, and a preponderance of large, $\mathrm{NH}_{4} \mathrm{Cl}$-sensitive receptor fields. The system then becomes more sensitive to sodium, apparently by the addition of functional amiloride-sensitive sodium channels to the taste receptor membrane, and gustatory afferent fibers have altered receptive field configurations, i.e. they innervate fewer papillae. Finally, at adulthood the system is highly responsive to sodium as reflected by large response frequencies and by most of the single fibers being maximally responsive to sodium rather than to other cations.

Other characteristics of the peripheral taste system change during the period of altering salt responses.
For example, chemical response latencies of afferent fibers decrease ${ }^{29}$ as the chorda tympani nerve is increasingly myelinated ${ }^{43}$.

The demonstration of a progressively emerging, environmentally susceptible sodium taste system appears to be reflected in the perception of salts in humans and in other mammals. As predicted from functional responses, rats seem capable of responding behaviorally to some taste stimuli soon after birth However, their responsiveness to salts changes dramatically during a prolonged period of development. For example, 5-day-old rats show no evidence of a preference for $\mathrm{NaCl}$ solutions over water, regardless of the $\mathrm{NaCl}$ concentration ${ }^{44}$. In contrast, rats aged 10 days actually prefer $\mathrm{NaCl}$ solutions that are aversive to adults ${ }^{44,45}$, and rats aged 25 days drink about three times as much of such solutions as do adults. Mature preferences and aversions for $\mathrm{NaCl}$ do not occur until much later in the rat's development, and the magnitude of aversion seen in adults is not exhibited until approximately 48 days of age ${ }^{46}$. Furthermore, early post-weaning rats are unable to discriminate between the tastes of $\mathrm{NaCl}, \mathrm{NH}_{4} \mathrm{Cl}$ and $\mathrm{KCl}$, whereas adults readily make such discriminations ${ }^{47}$. This indicates that the 'taste' of $\mathrm{NaCl}$ to young rats is not the same as it is to adults. Thus, age-related alterations in gustatory function in rat seem to be manifest in age-related alterations in the perception of $\mathrm{NaCl}$.

Such relationships may also occur in human development. Premature and full-term human newborns discriminate among taste stimuli and exhibit affective responses to acids, sugars and some bitter stimuli ${ }^{48}$. 
However, it has been difficult to demonstrate that the human newborn can detect and respond to $\mathrm{NaCl}$. Recent observations from developmental studies indicate that mature behavioral responses to $\mathrm{NaCl}$ (e.g. demonstration of the adult preference-aversion function) are not expressed until about 4 years of age ${ }^{49}$. Thus, there is a gradual shift in behavioral responses to various concentrations of $\mathrm{NaCl}$ during the first few years of life. A biological basis for these observations in humans is apparent in the documented neuroanatomical and neurophysiological emergence of the sodium taste system in animals. The broad window for neural maturation of salt taste provides a prolonged period for environmental interactions with intrinsic developmental processes.

\section{Selected references}

1 Heck, G. L., Persaud, K. C. and DeSimone, J. A. (1989) Biophys. J. 55, 843-857

2 Kinnamon, S. C. (1988) Trends Neurosci. 11, 491-496

3 Teeter, J. H. and Cagan, R. H. (1989) in Neural Mechanisms in Taste (Cagan, R. H., ed.), pp. 1-20, CRC Press

4 Hill, D. L. (1987) J. Neurophysiol. 57, 481-495

5 Bradley, R. M. and Mistretta, C. M. (1980) Brain Res. 191 21-34

6 Guth, L. (1957) Anat. Rec. 128, 715-731

7 Sloan, H. E., Hughes, S. E. and Oakley, B. (1983) J. Neurosci. 3, 117-123

8 Beidler, L. M. and Smallman, R. L. (1965) J. Cell Biol. 27, 263-272

9 Beidler, L. M. (1953) J. Neurophysiol. 16, 595-607

10 McBurney, D. H. and Shick, T. R. (1971) Percept. Psychophys. 10, 249-252

11 Morrison, G. R. (1967) Can. J. Psychol. 21, 141-152

12 Smith, D. V. and Frank, M. (1972) Physiol. Behav. 8, 213-220

13 Schiffman, S. S., Lockhead, E. and Maes, F. W. (1983) Proc Natl Acad. Sci. USA 80, 6136-6140

14 Brand, J. G., Teeter, J. H. and Silver, W. L. (1985) Brain Res. $334,207-214$

15 Heck, G. L., Mierson, S. and DeSimone, J. A. (1984) Science 223, 403-405

16 Avenet, P. and Lindemann, B. (1988) J. Membr. Biol. 105 245-255

17 Bradley, R. M. and Mistretta, C. M. (1973) I. Physiol. (London) 231, 271-282

18 Mistretta, C. M. and Bradley, R. M. (1983) /. Comp. Neurol. $215,199-210$

19 Nagai, T., Mistretta, C. M. and Bradley, R. M. (1988) J. Neurosci. 8, 64-72

20 Lichtman, J. W. (1977) J. Physiol. (London) 273, 155-177

21 Van Essen, D. C. (1982) in Neuronal Development (Spitzer N. C., ed.), pp. 333-371, Plenum Press

22 Mistretta, C. M., Gurkan, S. and Bradley, R. M. (1988) J. Neurosci. 8, 73-78

23 Mistretta, C. M. (1988) in The Beidler Symposium on Taste and Smell (Miller, I. J., Jr, ed.), pp. 21-31, Book Service Association

24 Farbman, A. I. (1965) Dev. Biol. 11, 110-135

25 Mistretta, C. M. (1972) in Oral Sensation and Perception Vol. 3: The Mouth of the Infant (Bosma, J. F., ed.), pp 163-187, Thomas

26 Ferrell, M. F., Mistretta, C. M. and Bradley, R. M. (1981) J. Comp. Neurol. 198, 37-44

27 Hill, D. L. and Almli, C. R. (1980) Brain Res. 197, 27-38

28 Yamada, T. (1980) Jpn. J. Physiol. 30, 631-643

29 Hill, D. L., Mistretta, C. M. and Bradley, R. M. (1982) J. Neurosci. 2, 782-790

30 Hill, D. L. (1988) J. Comp. Neurol. 268, 346-356

31 Hill, D. L. and Bour, T. C. (1985) Dev. Brain Res. 20, 310-313

32 Formaker, B. K. and Hill, D. L. (1988) Am. J. Physiol. 255. R1002-R1007

33 Hubel, D. H. and Wiesel, T. N. (1970) J. Physiol. (London) 206, 419-436

34 Kerr, L. M., Ostapoff, E. M. and Rubel, E. W. (1979) J. Exp. Psychol. (Anim. Behav. Process.) 5, 97-115

35 Hill, D. L. (1987) J. Physiol. (London) 393, 413-424
36 Hill, D. L., Mistretta, C. M. and Bradley, R. M. (1986) Behav Neurosci. 100, 390-398

37 Bird, E. and Contreras, R. J. (1987) Dev. Psychobiol. 20. $111-130$

38 Contreras, R. J. and Frank, M. E. (1979) J. Gen. Physiol. 181, 235-239

39 Hill, D. L. and Przekop, P. R., Jr (1988) Science 241, 1826-1828

40 Przekop, P. R. Jr Mook, D. G. and Hill, D. L (1988) Chem. Senses 4, 728-729

41 Bradley, R. M. (1973) Am. J. Physiol. 224, 300-304

42 Hosley, M. A., Hughes, S. E., Morton, L. L. and Oakley, B. (1987) J. Neurosci. 7, 2075-2080

43 Ferrell, M. F., Tsuetaki, T. and Chole, R. A. (1985) Acta Anat 123, 224-229

44 Moe, K. E. (1986) Dev. Psychobiol. 19, 185-196

45 Bernstein, I. L. and Courtney, L. (1987) Dev. Psychobiol. 20, 443-453

46 Midkiff, E. E. and Bernstein, I. L. (1983) Dev. Psychobiol. 16, 385-394

47 Formaker, B. K. and Hill, D. L. Behav. Neurosci. (in press)

48 Steiner, J. E. (1979) Adv. Child Dev. 133, 257-295

49 Beauchamp, G. K., Cowart, B. J. and Moran, M. (1986) Dev. Psychobiol. 19, 17-25

50 Carpenter, J. A. (1956) J. Comp. Physiol. Psychol. 49, 139-144

51 Denton, D. A. (1982) The Hunger for Salt Springer-Verlag

52 Wong, R. and Jones, W. (1978) Behav. Biol. 24, 474-480

53 Salber, P. and Zucker, I. (1974) Behav. Biol. 10, 295-311

54 Pujol, R. and Uziel, A. (1988) in Handbook of Human Growth and Developmental Biology, Vol. 1, Part B: Sensory, Motor and Integrative Development (Meisami, E. and Timiras, P. S., eds), pp. 109-130, CRC Press

\section{The Royal Society Election of New Fellows}

On 15 March 1990 the newly elected Fellows included the following neuroscientists. Trends in Neurosciences offers its congratulations on this honour, given in recognition of their distinguished contributions to research.

Professor David Anthony Brown. Professor and Head of the Department of Pharmacology at University College and Middlesex School of Medicine, London, UK. Distinguished for his elucidation of the mechanisms of action of neurotransmitters on peripheral neurones and in the brain.

Dr Andrew Charles Crawford. Reader in Physiology in the University of Cambridge, UK. Distinguished for discovering (with Dr R. Fettiplace) that the hair cells of the turtle's ear are sharply tuned to different frequencies, that their intracellular potentials resonate electrically at these frequencies, and that the hair bundles contain an active force-generating mechanism.

Dr Robert Fettiplace. Howe Senior Research Fellow of the Royal Society at the University of Cambridge, UK. In a series of remarkable experiments (with Dr A. Crawford) he analysed the electrical and mechanical properties of the hair cells of the turtle's ear.

Professor Semir Zeki. Professor of Neurobiology at University College London, UK. Distinguished for elucidating the anatomical regions of the cerebral cortex concerned with the analysis of the visual image, and for his demonstration that different areas are concerned primarily with colour and motion. 